Full Length Article

\title{
The influence of oxygen on the chemical composition and mechanical properties of Ti-6Al-4V during laser powder bed fusion (L-PBF)
}

\author{
Kai Dietrich ${ }^{\mathrm{a}, \mathrm{b}, *}$, Johannes Diller ${ }^{\mathrm{c}}$, Sophie Dubiez-Le Goff ${ }^{\mathrm{b}}$, Dominik Bauer ${ }^{\mathrm{b}}$, Pierre Forêt ${ }^{\mathrm{b}}$, \\ Gerd Witt ${ }^{\mathrm{a}}$
}

${ }^{a}$ University Duisburg-Essen, Lotharstraße 1, 47057, Duisburg, Germany

${ }^{\mathrm{b}}$ Linde AG, Carl-von-Linde-Straße 25, 85716, Unterschleißheim, Germany

${ }^{\mathrm{c}}$ Technical University Munich, Arcisstraße 21, 80333, München, Germany

\section{A R T I C L E I N F O}

\section{Keywords:}

Laser powder bed fusion (L-PBF)

Ti-6Al-4V

Atmosphere control

Oxygen

Mechanical properties

\begin{abstract}
A B S T R A C T
In Laser powder bed fusion (L-PBF), metal powders, sensitive to humidity and oxygen, like AlSi10Mg or Ti-6Al-4 $\mathrm{V}$ are used as starting material. Titanium-based materials are influenced by oxygen and nitrogen due to the formation of oxides and nitrides, respectively. During this research, the oxygen concentration in the build chamber was controlled from $2 \mathrm{ppm}$ to $1000 \mathrm{ppm}$ using an external measurement device. Built Ti-6Al-4 V specimens were evaluated regarding their microstructure, hardness, tensile strength, notch toughness, chemical composition and porosity, demonstrating the importance of a stable atmospheric control. It could be shown that an increased oxygen concentration in the shielding gas atmosphere leads to an increase of the ultimate tensile strength by $30 \mathrm{MPa}$ and an increased (188.3 ppm) oxygen concentration in the bulk material. These results were compared to hot isostatic pressed (HIPed) samples to prevent the influence of porosity. In addition, the fatigue behavior was investigated, revealing increasingly resistant samples when oxygen levels in the atmosphere are lower.
\end{abstract}

\section{Introduction}

Laser powder bed fusion (L-PBF) raised attention due to the high degree of flexibility of the process and its ability to produce lightweight components. A computer-aided design (CAD) model is sliced into layers and forms the basis for the rest of the process. Metal powder is distributed homogeneously onto a build platform made of a similar material before a laser melts the alloy following a bottom-up build approach layer by layer. Aluminum- and titanium-based alloys like AlSi7Mg, AlSi10Mg, Scalmalloy ${ }^{\circledast}$ or Ti-6Al-4 V are commonly used for aerospace applications and medical implants.

Ti-6Al-4 V is a widely used $\alpha+\beta$ alloy which is known for its enhanced processability and high strength at moderate to high temperatures. Aluminum stabilizes the $\alpha$-phase whereas vanadium stabilizes the $\beta$-phase. The alloy is highly reactive to oxygen and nitrogen, which changes the chemical and mechanical properties of the final component. To protect the material from ignition and oxidation, argon gas is used to establish an inert atmosphere before the laser powder bed process begins. Most machines work with a residual oxygen concentration of $1000 \mathrm{ppm}$ in the atmosphere leaving an equivalent nitrogen concentration of $3727 \mathrm{ppm}$. Oxygen has a high solubility (up to $14.2 \mathrm{wt}-\%$ as shown in Fig. 1) in the $\alpha$-phase and is, like nitrogen (7.6 wt-\% solubility), known to stabilize it [1]. Studies from BOYER ET AL (1994) and DONARCHIE (2000) show that an oxygen content of higher than $0.2 \mathrm{wt}-\%$ leads to a decrease in ductility and an increase in strength [2-4]. Decreasing interstitial elements improves ductility and resistance against crack growth and fracture toughness. The $\alpha$-phase increases hardness and strength, though also leads to a more brittle sample, whereas the $\beta$-phase improves ductility whilst reducing hardness and tensile strength [5].

In L-PBF high cooling rates of $10^{3}-10^{8} \mathrm{~K} / \mathrm{s}$ result in an acicular $\alpha^{\prime}$ martensitic microstructure $[4,8,9]$. The martensitic phase has the same chemical composition as the $\beta$-phase but its crystalline structure is hexagonal pseudo-compact resulting in high residual stresses [4]. Acicular $\alpha^{\prime}$ is the result of very fast cooling $\beta$-phase existing at solution temperature. Fig. 2 shows a phase diagram of the Ti-6Al-4 V system and its microstructure at different thermal influences.

$M_{S}$ and $M_{E}$ are the starting $\left(M_{S}\right)$ and ending $\left(M_{E}\right)$ points of the martensitic transformation. Above the $\beta$-transus temperature of $980{ }^{\circ} \mathrm{C}$ the lattice structure is body centered cubic (bcc) with a parameter of

\footnotetext{
* Corresponding author at: Linde AG, Carl-von-Linde-Straße 25, 85716, Unterschleißheim, Germany.

E-mail addresses: kai.dietrich@linde.com (K. Dietrich), johannes.diller@tum.de (J. Diller), sophie.dubiez-le.goff@linde.com (S. Dubiez-Le Goff), dominik.bauer@linde.com (D. Bauer), pierre.foret@linde.com (P. Forêt), gerd.witt@uni-due.de (G. Witt).
} 


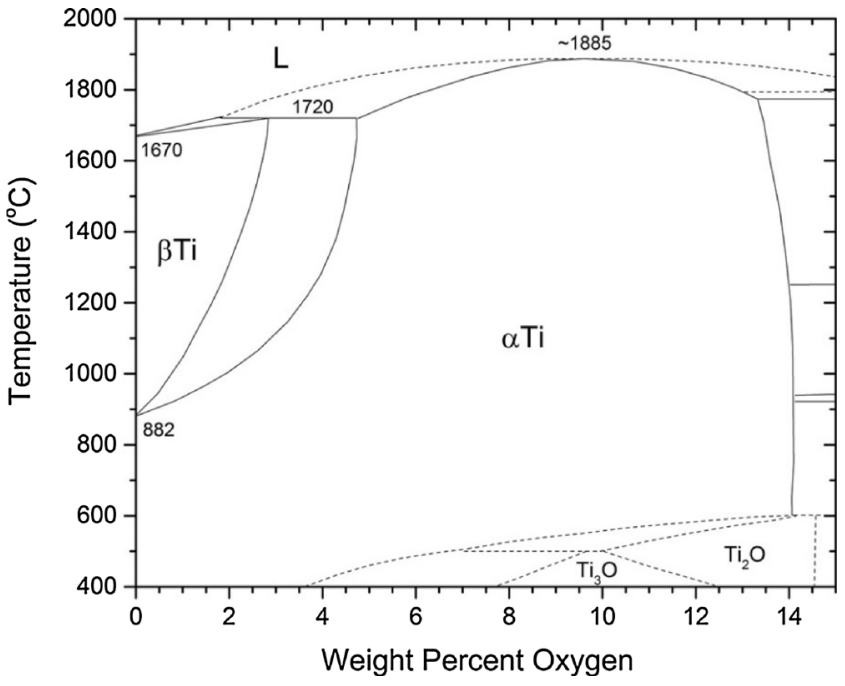

Fig. 1. Phase diagram of titanium and oxygen [6,7].

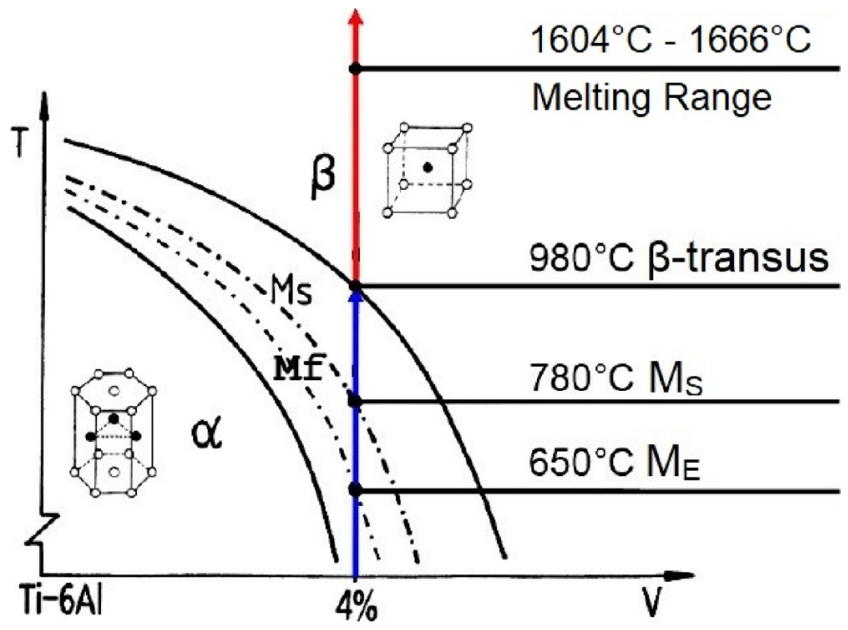

Fig. 2. Schematic pseudo-binary diagram of Ti-6Al-4 V [10].

$3.192 \AA$ [11]. Due to contractions induced by vanadium, which has smaller lattice parameters, the titanium lattice is shortened. At the temperature range of $1604{ }^{\circ} \mathrm{C}-1666{ }^{\circ} \mathrm{C}$ Ti-6Al-4 V starts to melt [12-16].

In this study, the importance of controlling the composition of the atmosphere during L-PBF is investigated. The commonly implemented lambda probes or galvanic sensors are known to be influenced by hydrogen which forms from humidity $\left(\mathrm{H}_{2} \mathrm{O}\right)$ in the powder $[17,18]$. An alternative system to maintain a stable oxygen concentration during the build process was used. Ti-6Al-4 $\mathrm{V}$ alloy is processed under different residual oxygen concentrations in the build atmosphere, and mechanical and chemical properties are assessed.

\section{Experimental method}

Advanced Plasma Atomized (APA ${ }^{\mathrm{TM}}$ ) Ti-6Al-4 V Grade 5 powder from AP\&C was used during this research. An EOS M290 that is connected with a Linde ADDvance ${ }^{\circledR} \mathrm{O}_{2}$ precision was used to precisely monitor and regulate the oxygen concentration in the build chamber by purging the build chamber with inert gas. A too low oxygen concentration was leveled out by leakages of the L-PBF machine. The build job design included 52 cubes $\left(8 \times 8 \times 10 \mathrm{~mm}^{3}\right)$ with various laser parameters, three notch impact bars $\left(13 \times 10 \times 55 \mathrm{~mm}^{3}\right)$, 15 Cylinders (length: $12 \mathrm{~mm}, \varnothing=3.5 \mathrm{~mm})$ and 10 bars for tensile testing $(13 \times 12$ $\times 60 \mathrm{~mm}^{3}$ ) as shown in Fig. 3 .

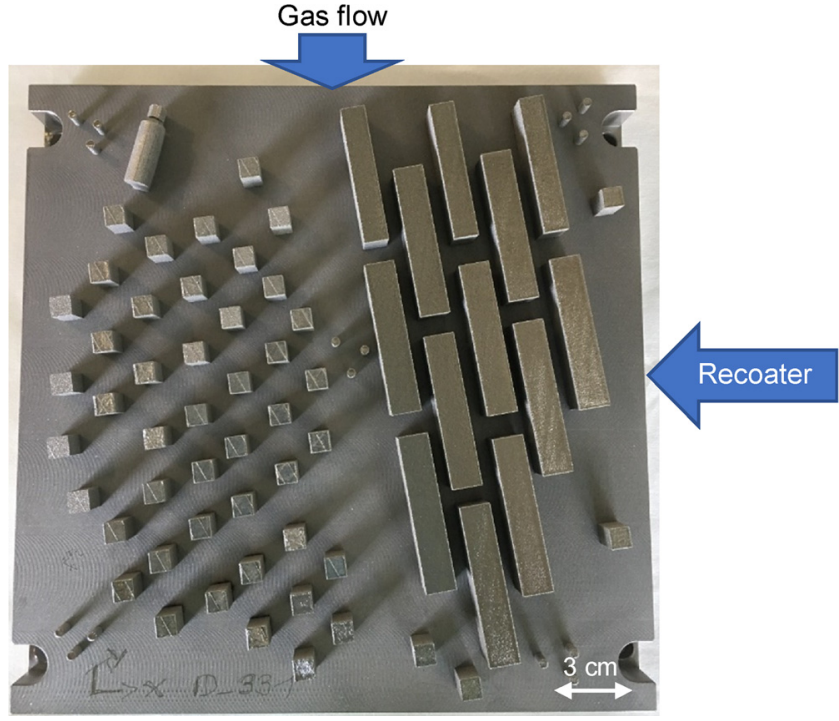

Fig. 3. Example of the finished build job.

Table 1

Used Laser Parameters for Ti-6Al-4 V on EOS M290.

\begin{tabular}{lllll}
\hline $\begin{array}{l}\text { Hatching } \\
\text { distance }[\mathrm{mm}]\end{array}$ & $\begin{array}{l}\text { Laser speed } \\
{[\mathrm{mm} / \mathrm{s}]}\end{array}$ & $\begin{array}{l}\text { Laser } \\
\text { Power }[\mathrm{W}]\end{array}$ & $\begin{array}{l}\text { Build Layer } \\
\text { Thickness }[\mu \mathrm{m}]\end{array}$ & $\begin{array}{l}\text { Oxygen } \\
{[\mathrm{ppm}]}\end{array}$ \\
\hline $0.09-0.19$ & $800-1600$ & $200-370$ & 30 & $0-1000$ \\
\hline
\end{tabular}

All samples, except the cubes were manufactured with the standard EOS parameter Ti64_PerformanceM291 1.10 with a build platform temperature of $30{ }^{\circ} \mathrm{C}$. A laser parameter study was performed on the cubes within the range listed in Table 1.

Its purpose was to investigate the optimal laser parameters for each oxygen concentration regarding the material density. Additional results regarding porosity and microstructure of the cubes form the basis of a separate study. The samples used for mechanical tests were stress relieved at $650{ }^{\circ} \mathrm{C}$ for $3 \mathrm{~h}$ in a vacuum furnace before cutting them off the build plate. The dimensions of the machined samples in accordance to the respective standards are shown in Figs. 4 and 5.

For fatigue measurements a new build job design was used (Fig. 6), to build all specimens on one platform at the same time. Three horizontal tensile bars $\left(13 \times 12 \times 60 \mathrm{~mm}^{3}\right)$ were added to determine the ultimate tensile strength. In addition, twelve cylinders (length: $12 \mathrm{~mm}$, $\emptyset=3.5 \mathrm{~mm})$ for chemical analysis and 15 horizontal bars $(83 \times 14 \times$ $14 \mathrm{~mm}^{3}$ ) for fatigue measurements were added. Mechanical testing samples were stress relieved in vacuum at $650{ }^{\circ} \mathrm{C}$ for $3 \mathrm{~h}$ before cutting them from the build plate. The $\mathrm{O}_{2}$ Precision was used to maintain 68 ppm and 1003 ppm oxygen in the atmosphere to determine whether oxygen holds any influence over fatigue behavior. For the following build jobs, the Ti-6Al-4 V powder was sieved and analyzed again.

Fatigue measurements were performed on a Roell Amsler REL 2041 with a load cell of $10 \mathrm{kN}$, according to DIN 50100. The tests were conducted at room temperature using samples machined to Type A shape, as specified in Fig. 7 and Table 2.

To investigate the influence of oxygen concentration in the build chamber on the final part quality, the build job was repeatedly built at different oxygen concentrations ( 0 ppm, 200 ppm, 400 ppm, 600 ppm). The different oxygen concentrations were reached by purging in additional inert gas using the ADDvance ${ }^{\circledR} \mathrm{O}_{2}$ precision to a defined setpoint and then maintained at the same level over the total build time. In addition, a build job without using the ADDvance ${ }^{\circledR} \mathrm{O}_{2}$ precision to control the oxygen level was built for further comparison as a benchmark. The ADDvance ${ }^{\circledast}$ system uses a chemical cell to measure the oxygen concentration with $\pm 1 \mathrm{ppm}$ deviation. Due to humidity in the 


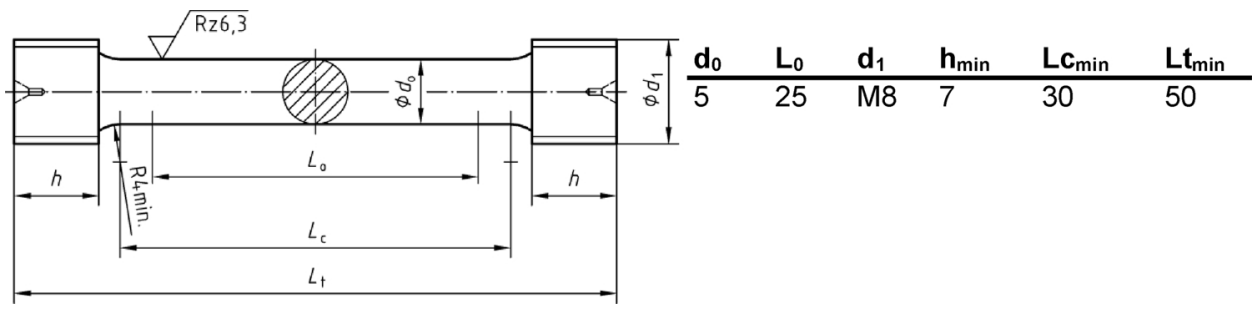

Fig. 4. Geometry and dimensions of used tensile specimen [19].

powder, hydrogen will form during the process. $\mathrm{H}_{2}$ is known to influence the measurement of Lambda and amperometric sensors leading to a deviation in the measurement results [17,22,23]. For oxygen measurements, the operating temperature of the sensors varies from $580{ }^{\circ} \mathrm{C}$ to $700{ }^{\circ} \mathrm{C}$. This could lead to a reaction of hydrogen and oxygen. Water formation on the sensor surface could deviate the actual oxygen concentration. An increased diffusion rate of hydrogen also influences the measurement [22].

To determine the chemical composition of oxygen, nitrogen and hydrogen, the carrier gas hot extraction (CGHE) ONH 836 from LECO was used on as-built samples. Porosity was measured by hot embedding and polishing, followed by digital image capture with a Keyence VHX6000 microscope. Multiple pictures taken during a scan of the sample were digitally stitched together to produce a high-resolution image of the surface. Vickers hardness HV10 was measured using a DuraScan from Struers according to DIN EN ISO 6507-1:2018. The measurements were performed on the cubes surrounding the tensile specimen and taken diagonally from the top left corner to the bottom right, using a load of $10 \mathrm{~kg}$. To investigate whether heat treated samples are affected by different oxygen concentrations during production, only half of the tested cubes were heat treated. Scanning electron microscope (SEM) images were taken using a VEGA3 LMH built by TESCAN with a silicon drift detector X-MaxN from Oxford Instruments. Charpy impact tests were conducted with a Roell Amsler RKP 300 following the ASTM B925-15 standard. With a Retsch Camsizer X2, the particle size distribution (PSD) was measured. Tensile tests were conducted according to DIN EN ISO 6892-1 (02-2017) using a Zwick Roell RetroLine Z100kN. The build cylinders were machined according to test shape B (Table 3). For each data point 5 specimens were tested to increase validity.

In addition, hot isostatic pressing (HIPing) removed the influence of porosity from 5 samples. Table 4 shows the established parameters.

The samples were machined according to test shape B (Table 3 ) and tested according to DIN EN ISO 6892-1 (02-2017). A Phillips PANalytical X'Pert PRO with an average wavelength of $0.15418 \mathrm{~nm}$ and a copper $(\mathrm{Cu})$ radiation cell was used for X-ray diffraction measurements.

\section{Results}

The build jobs were performed at different oxygen concentrations in the build chamber (2 ppm, 200 ppm, 399 ppm, 600 ppm). Due to leakages of the used L-PBF machine, 0 ppm oxygen during the build job could not be achieved whilst flushing with $50 \mathrm{l} / \mathrm{min}$. Hence the oxygen concentrations obtained are an average value over the whole build time fluctuating by $\pm 5 \mathrm{ppm}$. The build jobs were started after reaching a stable value of the adjusted oxygen concentration.

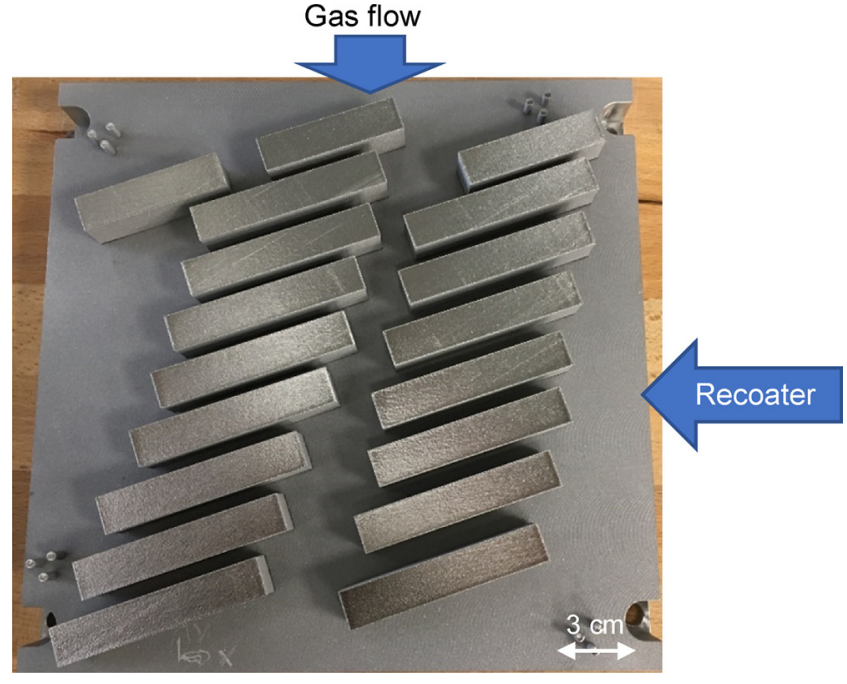

Fig. 6. Build Job design for horizontal fatigue jobs.

\subsection{Powder characterization}

The Ti-6Al-4 V Grade 5 powder was sieved before each build job to remove oversized particles forming due to particle sintering during the L-PBF process [24,25]. Agglomerated particles would increase the particle size distribution which effects the final part quality [26,27]. Before each build job particle size distribution and chemical composition of the powder were analyzed. The results of the virgin powder are shown in Table 5.

The SEM image of the powder (Fig. 8) reveals highly spherical particles This is a key criterion for good powder flowability and therefore provides process stability [28]. Particles of different sizes can be found which contributes to an increased packing density [29,30].

\subsection{Chemical analyses}

The deviations in chemical composition of the built parts regarding the oxygen concentration in the build chamber was measured by carrier gas hot extraction. By changing the chemistry of a material, an alteration in mechanical properties is expected [31,32]. Oxygen and nitrogen, with their rather small Van-der-Waals-radii of $152 \mathrm{pm}$ and $155 \mathrm{pm}$ respectively, can occupy the voids of the titanium crystal structure [33]. Fig. 9 shows that more residual oxygen, and therefore more residual nitrogen in the process gas atmosphere during L-PBF leads to an increased pickup of these elements into the material. Purging the L-PBF machines until an oxygen concentration of $1000 \mathrm{ppm}$ is reached will also leave an equivalent concentration of $3727 \mathrm{ppm}$ nitrogen in the

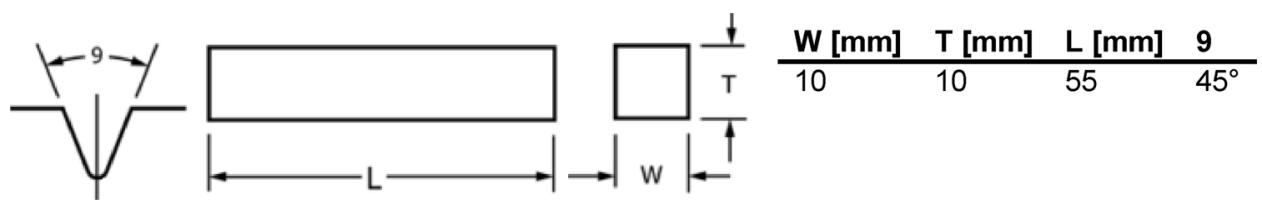

Fig. 5. Geometry and dimensions of used notch impact test specimen [20]. 


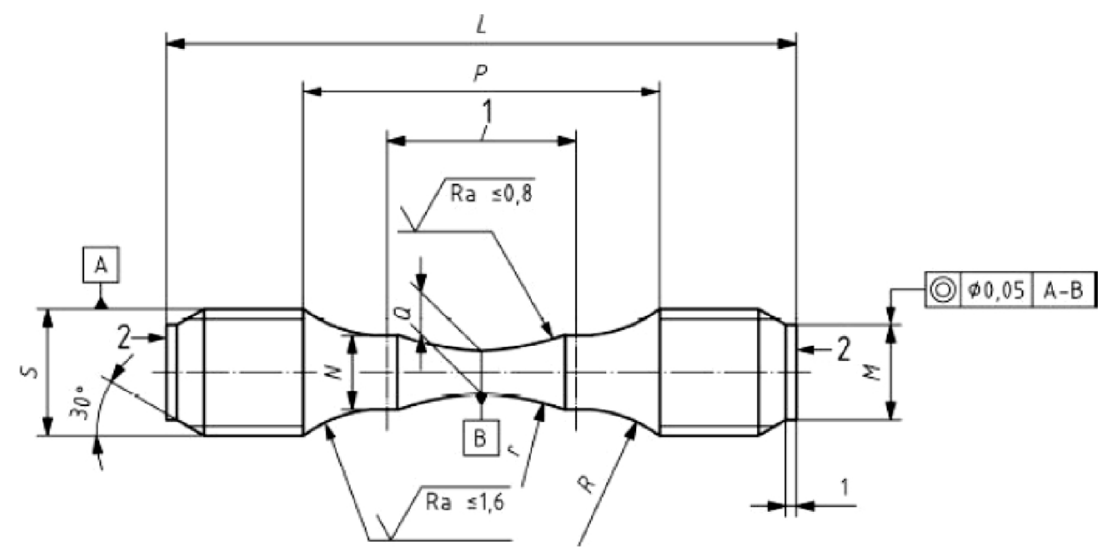

Fig. 7. Geometry of used fatigue sample [21].

build chamber. 15 cylinders (length: $12 \mathrm{~mm}, \varnothing=3.5 \mathrm{~mm}$ ) were spread over the build platform in groups of three to get an overall average, which is shown in Fig. 9. Nitrogen concentration increased from 62.2 ppm in the powder to $200.4 \mathrm{ppm}$ in the benchmark job, whereas oxygen concentration only increased by $41 \%$ compared to the virgin powder. The hydrogen concentration in the bulk material was not affected by the altered oxygen concentration.

\subsection{Structural analysis}

\subsubsection{Porosity measurement}

For density measurements, one cube $\left(8 \times 8 \times 10 \mathrm{~mm}^{3}\right)$ for each oxygen concentration built with EOS parameters was embedded, ground and investigated with a digital light microscope. In Fig. 10, the density is shown for different oxygen concentrations in the build chamber.

The resulting density for the different build jobs was higher than $99.92 \%$. According to the given results, the oxygen concentration in the atmosphere does not influence the density of the final component.

\subsubsection{Microstructure}

The microstructure of Ti-6Al-4 V was investigated by immersing the stress relieved samples in Kroll's etchant (ASTM E407 [34]) for $35 \mathrm{~s}$. Figs. 11 and 12show a typical microstructure of L-PBF processed Ti-6Al$4 \mathrm{~V}$ which could be columnar prior- $\beta$ grains according to YANG ET AL. $[4,9,35,36]$.

Comparing the microstructures obtained at $2 \mathrm{ppm}$ and $977 \mathrm{ppm}$ reveals the common fine lamellar structures off additively manufactured parts [37]. Highlighted spots in Fig. 12 features pores in the material. Higher magnification (500x) of the low oxygen sample could be seen in Fig. 13. It shows a typical basketweave structure which is assumed to be $\alpha^{\prime}$-martensite formed inside the prior- $\beta$ grains [11].

Increasing the magnification reveals the typical basketweave structure, which can be classified as $\alpha^{\prime}$-martensite [5]. E. SALLICA-LEVA et al. investigated the effect of sub- $\beta$-transus heat treatment on mechanical properties of Ti-6Al-4 V porous structures manufactured by LPBF. During their research they discovered that the $\beta$-phase starts to precipitate after $2 \mathrm{~h}$ at $650{ }^{\circ} \mathrm{C}$ at as-processed conditions based on XRD and SEM investigations [38]. At this magnification, it is not possible to detect any $\beta$-phase precipitation.

At the high temperatures of $920^{\circ} \mathrm{C}$ during hot isostatic pressing, $\beta$ -
Table 3

Tensile test shape B according to DIN EN ISO 6892-1.(02-2017)

\begin{tabular}{cccccc}
\hline $\mathrm{d}_{0}$ & $\mathrm{~L}_{0}$ & $\mathrm{~d}_{1}$ & $\mathrm{~h}_{\text {min }}$ & $\mathrm{L}_{\text {Cmin }}$ & $\mathrm{L}_{\text {tmin }}$ \\
\hline 5 & 25 & M8 & 7 & 30 & 60 \\
\hline
\end{tabular}

Table 4

Parameter for hot isostatic pressing of Ti-6Al-4 V tensile samples.

\begin{tabular}{lll}
\hline Temperature & Pressure & Time \\
\hline $920{ }^{\circ} \mathrm{C} \pm 10$ & 1000 bar $-0 /+50$ & $120 \min 0 /+30$ \\
\hline
\end{tabular}

phase is formed. Fig. 14 shows the microstructure of the obtained samples.

Due to the HIP process, the microstructure consists of $\alpha$ - and $\beta$ phase. The $\alpha$-phase is depicted in brighter colors whereas the $\beta$-phase is darker [39].

\subsection{X-ray diffraction}

The obtained phase composition was confirmed using X-Ray diffraction (XRD). It was assumed, that the microstructure mainly contains $\alpha$-structure with only a fractional amount of $\beta$ in between the grain boundaries. For data interpretation Powder Diffraction Files (PDF) cards 00-044-1294 and 00-009-0098 as well as literature was used as there are no typical cards for L-PBF manufactured Ti-6Al-4 V [32,40-43]. Fig. 15 shows the obtained XRD patterns for $2 \mathrm{ppm}$ and 977 ppm oxygen.

The peaks in the XRD scan are labeled with their respective planes notated in the Miller 3 -index. Fig. 16 shows the corresponding planes of the $\alpha$ - and $\beta$-phase

Both patterns look similar and could be identified as $\alpha / \alpha^{\prime}$ phase. Due to the similar lattice parameter and the hexagonal closed-packed structure, distinguishing between both is not clear with XRD [42,45]. Between the $\alpha 002$ and $\alpha 101$ plane in the $2 \mathrm{ppm}$ pattern a shoulder can be found. In literature the $\alpha 110$ planes is identified as $\beta$-phase $[45,46]$.

Table 2

Dimensions of fatigue specimen according to DIN EN 6072. All dimensions in mm [21].

\begin{tabular}{llllllllllll}
\hline Cross section $\left[\mathrm{mm}^{2}\right]$ & $\mathrm{L}$ & $\mathrm{M}$ & $\mathrm{N}$ & $\mathrm{P}$ & $\mathrm{Q}$ & $\mathrm{R}$ & $\mathrm{S}$ & Type & $\mathrm{K}_{\mathrm{t}}$ & $\mathrm{r}$ & Tolerance for $\mathrm{r}$ \\
\hline 12.5 & 80 & 9 & 7 & 34 & 3.99 & 13 & $\mathrm{M} 12$ & $\mathrm{~A}$ & 1.035 & 28 & \pm 0.5 \\
\hline
\end{tabular}


Table 5

Particle size distribution and chemical properties of virgin Ti-6Al-4 V Grade 5 powder.

\begin{tabular}{|c|c|c|c|c|c|c|c|c|c|}
\hline $\mathrm{Al}[\%]$ & V [\%] & $\mathrm{Fe}[\%]$ & C [\%] & $\mathrm{O}_{2}[\mathrm{ppm}]$ & $\mathrm{N}_{2}[\mathrm{ppm}]$ & $\mathrm{H}_{2}$ [ppm] & $\mathrm{D} 10[\mu \mathrm{m}]$ & $\mathrm{D} 50[\mu \mathrm{m}]$ & $\mathrm{D} 90[\mu \mathrm{m}]$ \\
\hline 6.64 & 4.25 & 0.21 & 0.01 & 1308.0 & 62.2 & 17.2 & 19.9 & 31.7 & 43.0 \\
\hline
\end{tabular}

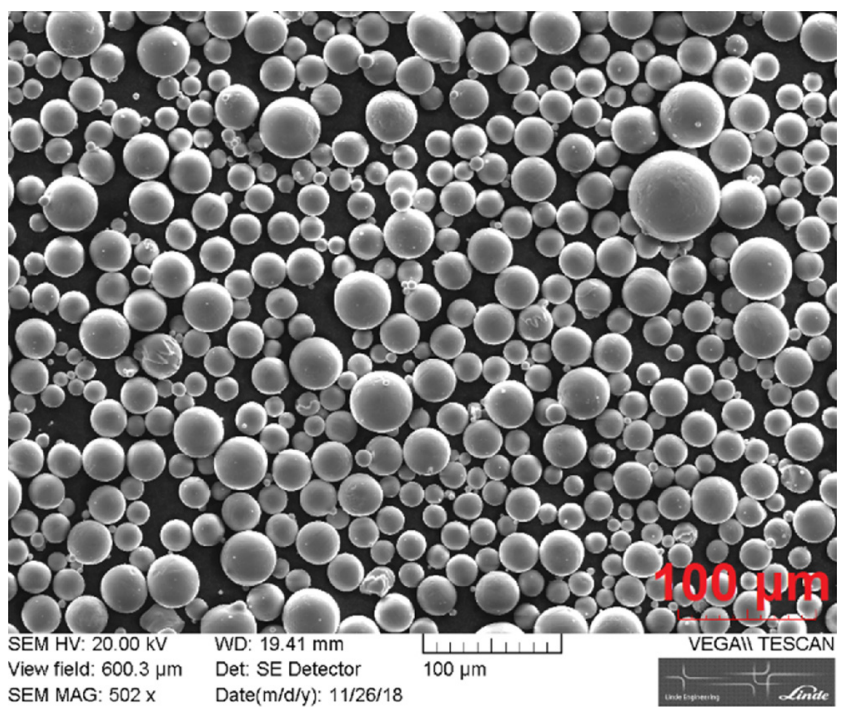

Fig. 8. SEM image of virgin Ti-6Al-4 V powder.

\subsection{Mechanical testing}

\subsubsection{Hardness}

Fig. 17 demonstrates hardness tests performed on as-built, stress relieved and HIPed cubes.

When measuring the range of deviations of the Vickers HV10 method, no significant trend could be found with reference to oxygen concentration. It is assumed that the indentations on the cubes were covering multiple grain orientations as well as smaller pores which resulted in high standard deviations. This was proved by comparing Vickers HV0.3 hardness of darker (386 HV0.3) and brighter (397 HV0.3) regions.

Stress relieved samples show an increased hardness in comparison to as-built specimens. One possible assumption is the presence of the intermetallic $\mathrm{Ti}_{3} \mathrm{Al}$ - or $\alpha 2$-phase. THIJS ET AL. state that dark bands with an aluminum concentration of at least $25 \%$ can occur at $500-600{ }^{\circ} \mathrm{C}$ due to the fast solidification during the L-PBF process. They proved the formation of the $\mathrm{Ti}_{3} \mathrm{Al}$-phase in this region using energy dispersive $\mathrm{X}$ ray (EDX) measurements. [47]

HIPed samples display a decreased Vickers hardness due to the increased amount of $\beta$-phase.

\subsubsection{Notch impact tests}

Notch impact tests were conducted regarding the ASTM E23 standard with a sample size of $55 \times 10 \times 10 \mathrm{~cm}$. The notch was machined after stress relief. Average values over three samples for each oxygen concentration are shown in Fig. 18.

Results for $399 \mathrm{ppm}$ are missing due to part failure during the process. The notch impact energy is in the same range as known to literature (11.5 $\mathrm{J}$ for as-built, $15 \mathrm{~J}$ for cast alloy) $[48,49]$. No significant trend could be found with reference to varying oxygen concentrations. The influence of oxygen on the impact toughness of horizontally manufactured samples is smaller than the standard error.

\subsubsection{Tensile tests}

Fig. 19 shows the increase in the ultimate tensile strength with increasing oxygen concentration when comparing stress relieved samples to those that underwent hot isostatic pressing. Due to the high pressure and temperature, the existing pores inside the samples are considered closed (density: $99.99 \%$ ).

With increasing oxygen concentration during the L-PBF process from 2 to $600 \mathrm{ppm}$, an increase in ultimate tensile strength (UTS) of around $30 \mathrm{MPa}$ was observed. The elongation decreased by up to $2.1 \%$ in total. The ultimate tensile strength from $2 \mathrm{ppm}$ to $600 \mathrm{ppm}$ increases from $1203 \mathrm{MPa}$ to $1217 \mathrm{MPa}$ with a negligible standard error. A similar trend can be observed for the Yield Strength Rp0.2. The benchmark build job has an ultimate tensile strength of $1058 \mathrm{MPa}$ with an increased standard error, which could be attributed to an unstable oxygen concentration during the build job. HIPed samples do have a decreased UTS and $\mathrm{R}_{\mathrm{p} 0.2}$, both around $200 \mathrm{MPa}$ less. This is, due to the increased amount of $\beta$-phase in the microstructure. With an increase in oxygen in the build chamber from $2 \mathrm{ppm}$ to $600 \mathrm{ppm}$ the UTS increases by 21

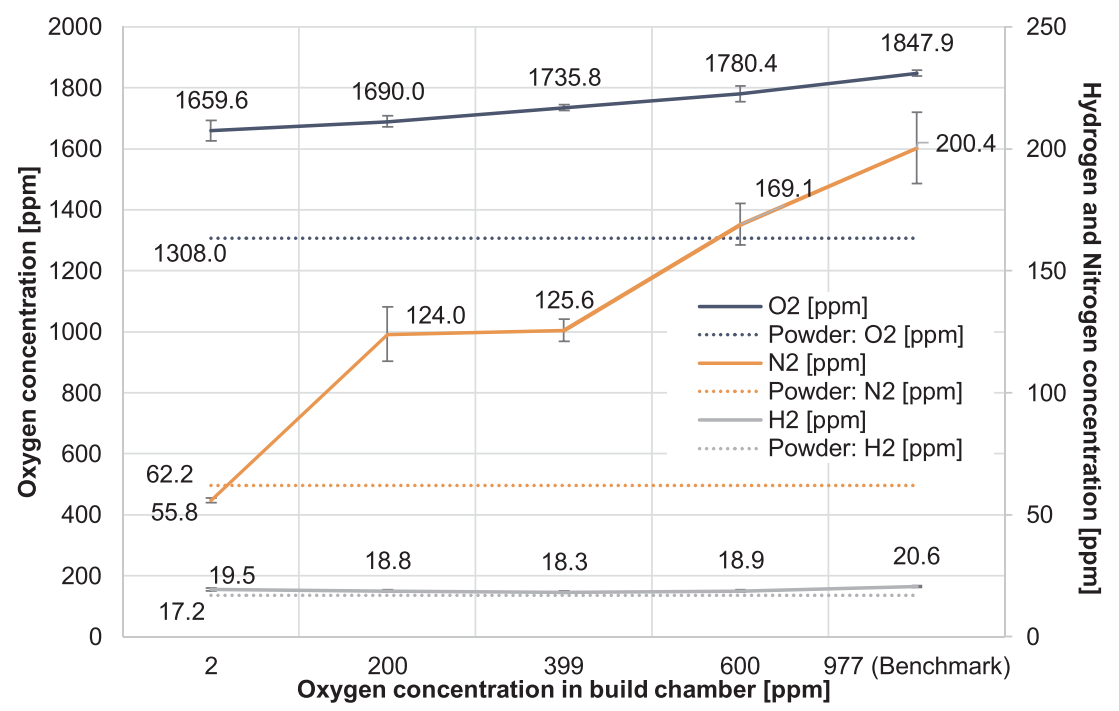

Fig. 9. $\mathrm{N}_{2}, \mathrm{O}_{2}$ and $\mathrm{H}_{2}$ concentration of the bulk material in relation to the oxygen concentration in the build atmosphere during L-PBF. 


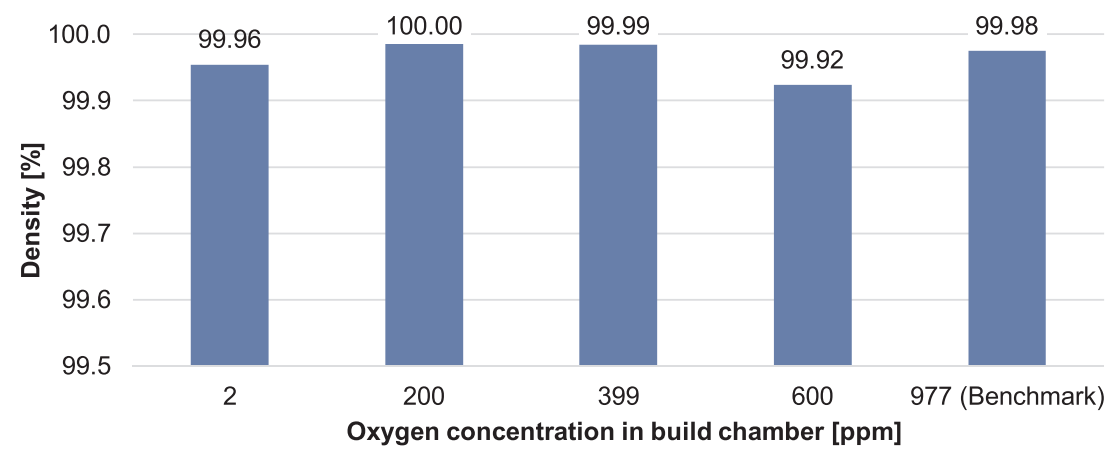

Fig. 10. Density of cubes built at different oxygen concentrations using EOS standard parameter.

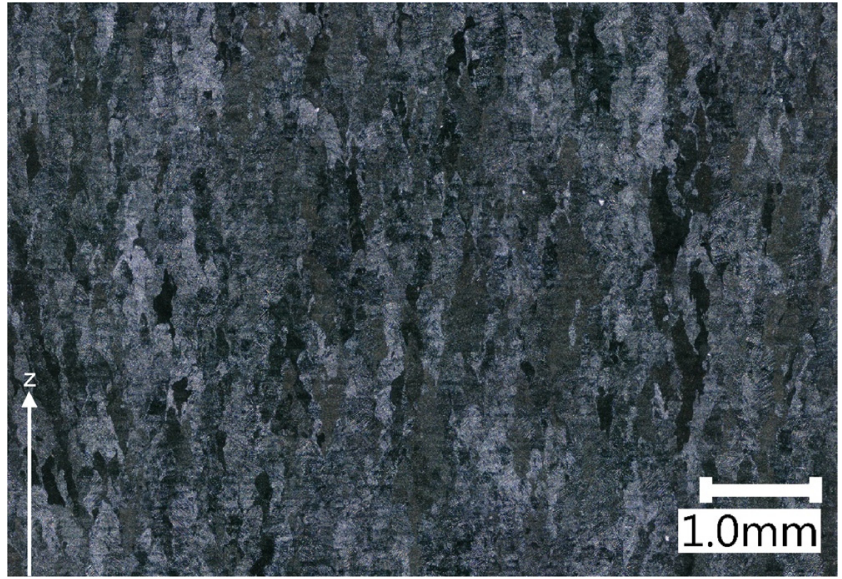

Fig. 11. Microstructure of $2 \mathrm{ppm} \mathrm{O2} \mathrm{sample} \mathrm{built} \mathrm{with} \mathrm{EOS} \mathrm{parameter}$ Ti64_PerformanceM291 1.10 in z-direction, stress relieved.

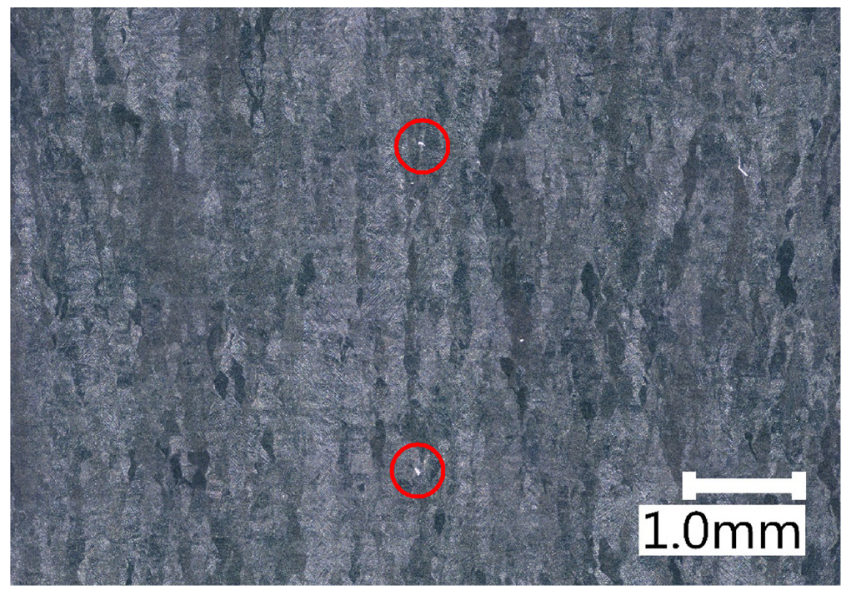

Fig. 12. Microstructure of 977 ppm (Benchmark) O2 sample built with EOS parameter Ti64_PerformanceM291 1.10 in z-direction, stress relieved, red circle highlights pores (For interpretation of the references to colour in this figure legend, the reader is referred to the web version of this article).

MPa. The ductility, however is more than two times the heat-treated samples; increased to $16.8 \%$ and is stable for the atmosphere-controlled build jobs. With a decreased elongation by $2.5 \%$ and an increased standard deviation (1.56\%), the benchmark job differs from the others. The standard error is $\pm 1.78 \mathrm{MPa}$ UTS and $\pm 3.94 \mathrm{MPa} \mathrm{R}_{\mathrm{p} 0.2}$ for all the samples except the benchmark job, the error for which was $\pm 38.54 \mathrm{MPa}$ UTS and $\pm 3.07 \mathrm{MPa} \mathrm{R}_{\mathrm{p} 0.2}$. The same trend in deviation in the standard error can be observed for the elongation.

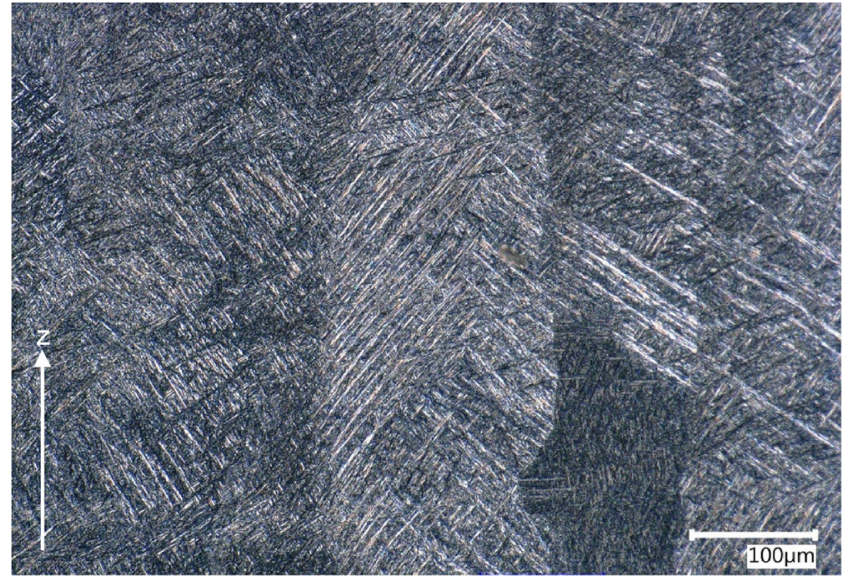

Fig. 13. Microstructure of $2 \mathrm{ppm} \mathrm{O} 2$ sample built with EOS parameter Ti64_PerformanceM291 1.10 in z-direction, stress relieved.

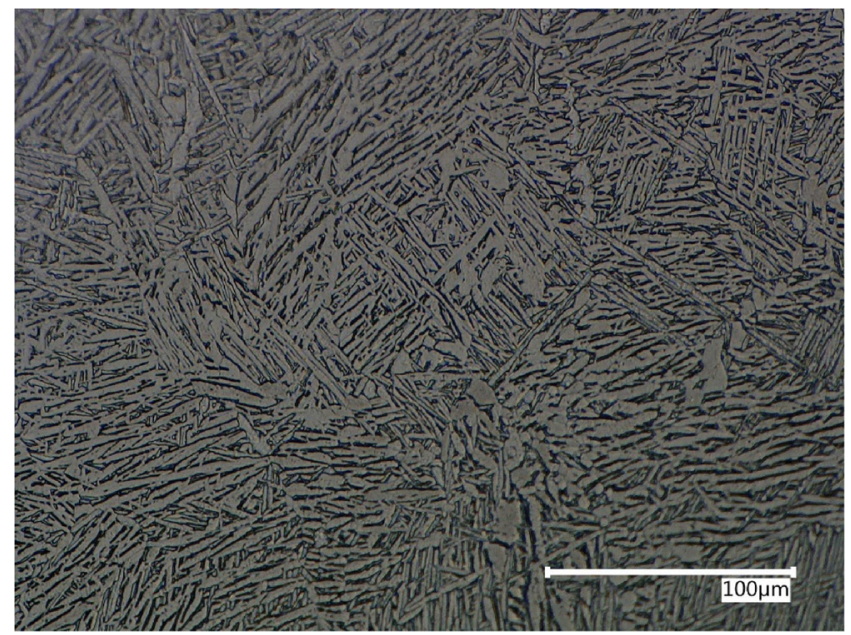

Fig. 14. Microstructure of $2 \mathrm{ppm} \mathrm{O} 2$ sample built with EOS parameter Ti64_PerformanceM291 1.10 in z-direction, HIP treated.

\subsection{Fatigue testing}

For the second test series the powder was sieved and analyzed. Obtained powder properties are shown in Table 6.

Compared to the virgin powder, the particle size distribution shifts towards coarser particles due to the formation of agglomerations during the build process [50,51]. Fig. 20 shows agglomerated particles in the one-time sieved powder. The oxygen concentration increased from $1308 \mathrm{ppm}$ from the virgin powder to $1347 \mathrm{ppm}$ which is still compliant with the ASTM B348 standard ( $<2000$ ppm) [52]. 


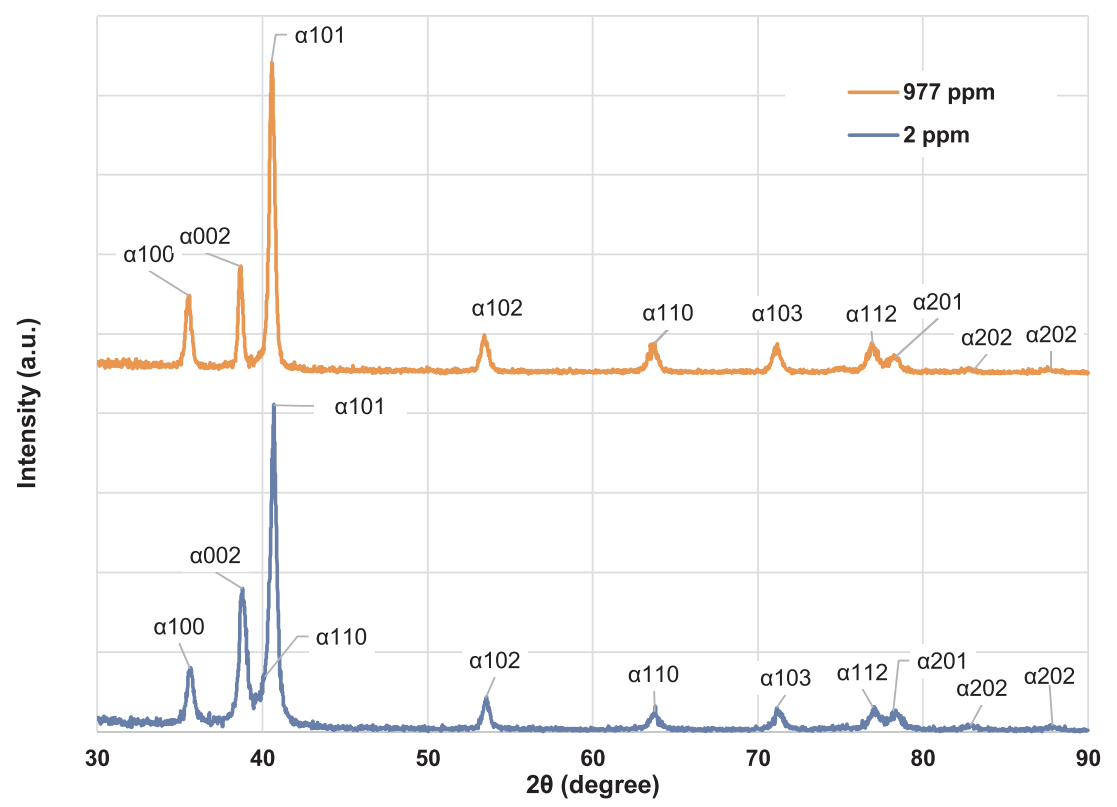

Fig. 15. XRD patterns for L-PBF Ti-6Al-4 V manufactured at 2 ppm and 977 ppm oxygen in the build chamber; stress relieved.

\subsubsection{Chemical analysis}

Obtained results for oxygen, nitrogen and hydrogen concentration in the bulk material of samples built with the fatigue samples are shown in Fig. 21.

An increase of oxygen in the build atmosphere correlates to the changes in chemical composition of the final parts. The nitrogen concentration increases by up to $138 \%$ in comparison to the powder, and oxygen concentration increases by up to $29 \%$. The hydrogen concentration appears to be independent from the oxygen concentration. These results are similar to the observation in section 3.5.3 demonstrating the reproducibility of this trend (1660 ppm $\mathrm{O}_{2}$ (2 ppm build job), $1848 \mathrm{ppm} \mathrm{O}_{2}$ (977 ppm build job)).

\subsubsection{Tensile strength}

For the initial fatigue test, the ultimate tensile strength must be determined. The tensile strength of samples built with the fatigue samples is shown in Fig. 22.

Whilst increasing the oxygen concentration in the atmosphere from $68 \mathrm{ppm}$ to $1003 \mathrm{ppm}$, an increase in tensile strength of $34 \mathrm{MPa}$ was observed. This confirms the results from section 3.5.3 showing the reproducibility of this trend (1002 MPa (2 ppm Build Job), $1058 \mathrm{MPa}$ (977 ppm Build Job)). The yield strength follows this trend, whereas elongation is constant at $4.9 \%$.

\subsection{3. $S N$-Curves}

For $68 \mathrm{ppm}$ and $1003 \mathrm{ppm}$ of $\mathrm{O}_{2}$ during the build job, 12 samples were measured. Fig. 23 shows the final results. The number of cycles was plotted against the maximum stress. Samples marked with an arrow were stopped before rupture. The tests were conducted in the range for pulsating tensile stresses with $\mathrm{R}=0.1$. Comparing the lowest and highest oxygen level during L-PBF in relation to the fatigue behavior, the influence of the residual gases on the final part quality could be inferred. Samples produced at $68 \mathrm{ppm} \mathrm{O}_{2}$ tend to withstand more cycles before failing than samples obtained at $1003 \mathrm{ppm} \mathrm{O}_{2}$. This is likely to be because of increased oxygen and nitrogen concentration in the specimen leading to increased embrittlement. The SN-curve of 68 ppm exhibits an accumulation of data points in between $1+$ E06 and 2 + E06 cycles, whereas the data points of 1003 ppm are more frequently agglomerated in between $3+$ E05 and $1+$ E06 cycles. The fracture surface is investigated in section 3.6.4.

\subsubsection{Fracture surface investigations}

Scanning electron microscopy was performed to investigate crack initiation on the fatigue samples. Surface and subsurface porosity was
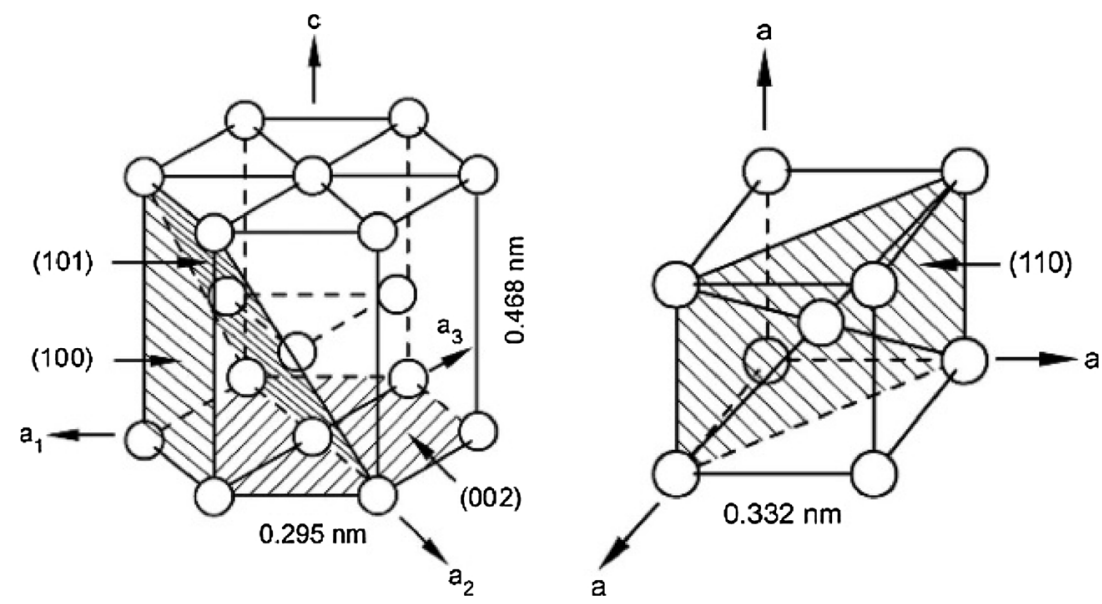

Fig. 16. Unit cell of hep $\alpha$-phase (left) and bcc $\beta$-phase (right) [44]. 


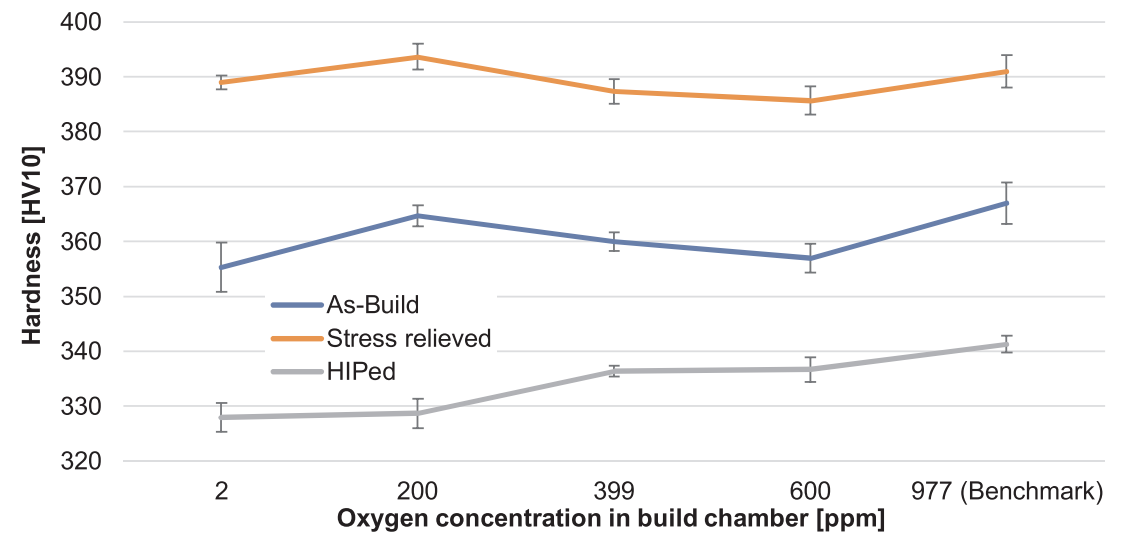

Fig. 17. Vickers Hardness HV10 of as built, stress relieved and HIP treated Ti-6Al-4 V cubes.

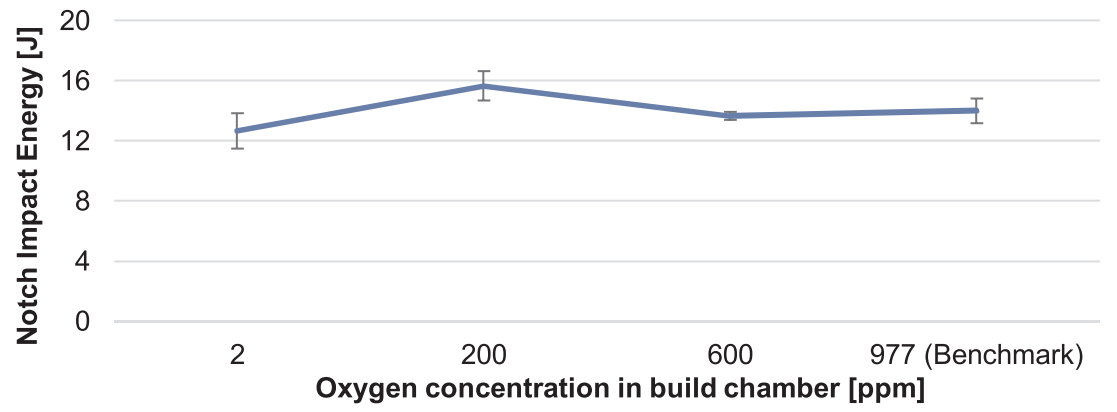

Fig. 18. Notch impact test in relation to the oxygen concentration in the atmosphere.

identified as the reason for crack initiation independent of the oxygen concentration in the build chamber as shown in Fig. 24.

A1 shows a half-moon-shaped forced rupture on the bottom left corner indicating a crack initiation on the opposite side [53]. Higher magnification (A2) reveals a non-fused particle in a pore close to the surface. Specimens manufactured at lower oxygen concentrations in the build chamber were subject to the same crack initiation reasons. B2 unveils a process related pore.

\section{Discussion}

During this project Ti-6Al-4 V samples were manufactured at different oxygen concentrations in the build chamber (2 ppm-600 ppm, benchmark at $977 \mathrm{ppm})$. Whilst argon is purged in the build chamber, air is suppressed until an oxygen concentration of $1000 \mathrm{ppm}$ is reached.
The atmosphere is not completely replaced whereas an equivalent of nitrogen in the build chamber remains as well. Built parts were investigated with reference to chemical composition and mechanical properties. For mechanical testing the samples were stress relieved in a vacuum furnace at $650{ }^{\circ} \mathrm{C}$ for $3 \mathrm{~h}$. Due to high cooling rates during LPBF the microstructure is acicular $\alpha^{\prime}$-martensitic. Porosity measurements showed an overall density higher than $99.92 \%$ which was considered sufficient for mechanical testing.

The effect of oxygen on the yield and tensile strength, the elongation as well as the impact strength of commercial pure titanium grade $1-4$ is shown in Fig. 25.

WASZ ET AL could show that with increasing oxygen concentration, the yield and tensile strength increases, while the elongation decreases. The impact strength increases up to an oxygen concentration of $0.25 \mathrm{wt}-\%$ while significantly decreasing with higher oxygen. $\mathrm{O}_{2}$ behaves as an

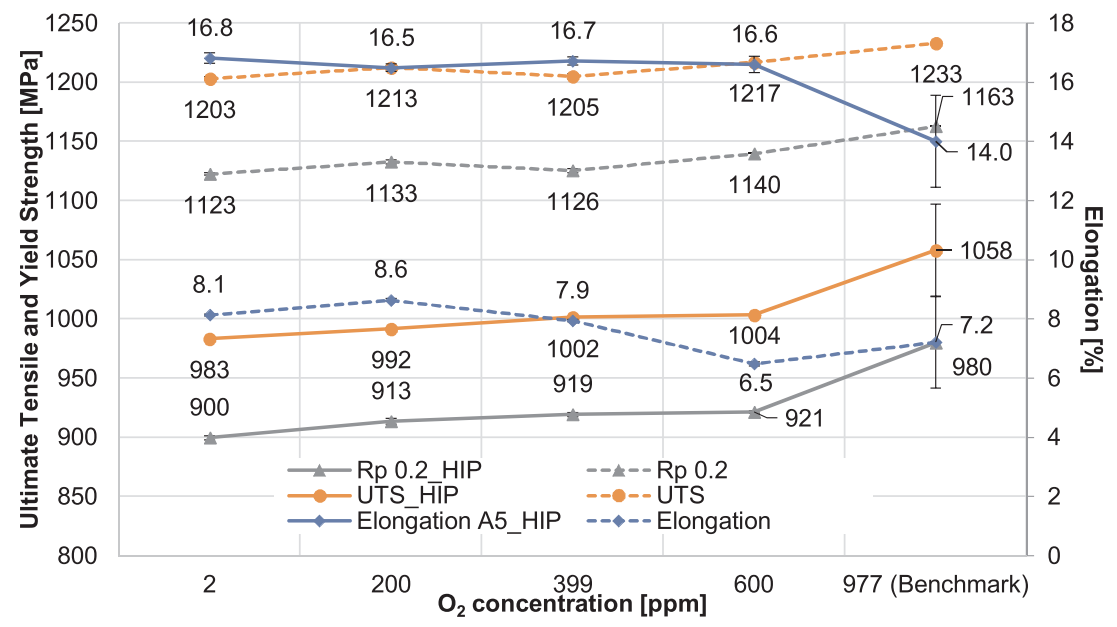

Fig. 19. Tensile strength and elongation of stress relieved (dotted line) and HIPed (straight line) samples in relation to the oxygen concentration in the atmosphere. 
Table 6

Particle size distribution and chemical properties of Ti-6Al-4 V Grade 5 powder for fatigue testing.

\begin{tabular}{|c|c|c|c|c|c|c|c|c|c|}
\hline $\mathrm{Al}[\%]$ & V [\%] & $\mathrm{Fe}[\%]$ & C [\%] & $\mathrm{O}_{2}[\mathrm{ppm}]$ & $\mathrm{N}_{2}[\mathrm{ppm}]$ & $\mathrm{H}_{2}[\mathrm{ppm}]$ & $\mathrm{D} 10[\mu \mathrm{m}]$ & $\mathrm{D} 50[\mu \mathrm{m}]$ & $\mathrm{D} 90[\mu \mathrm{m}]$ \\
\hline 6.64 & 4.25 & 0.21 & 0.01 & 1347.7 & 102.8 & 18.8 & 20.5 & 32.1 & 44.1 \\
\hline
\end{tabular}

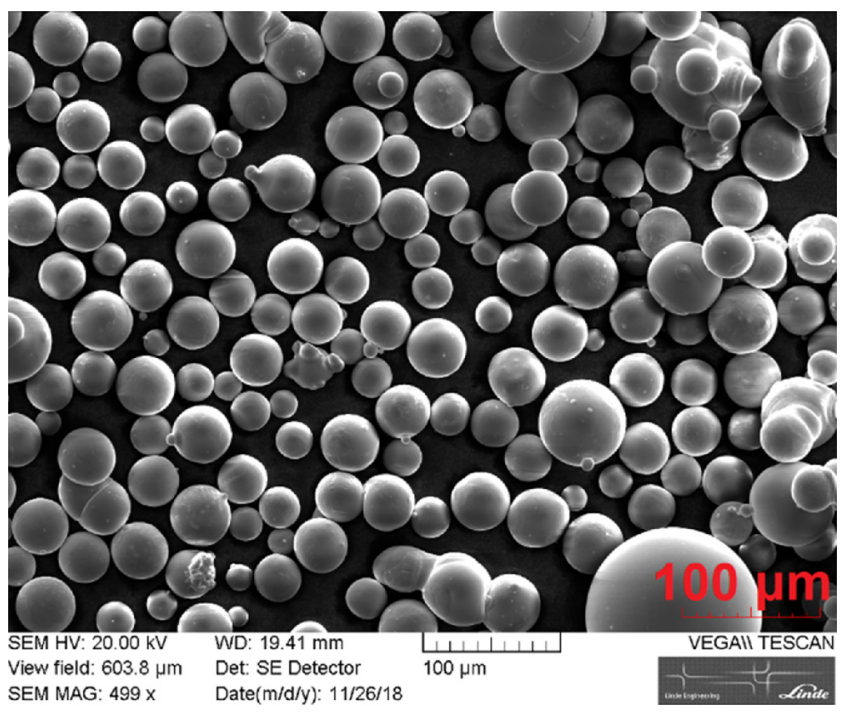

Fig. 20. SEM image of Ti-6Al-4 V powder for fatigue testing at 499x magnification.

interstitial element in the microstructure, impeding dislocation motion and inhibiting low temperature twinning [44,55]. In L-PBF, the parts are built layer by layer, resulting in a repeating exposure to the atmosphere in the build chamber. Therefore, on every layer, formation of oxides is possible.

The chemical composition shows an increase in oxygen pickup from the powder (1308 ppm) to the bulk material build at $2 \mathrm{ppm}(1660 \mathrm{ppm})$ to $977 \mathrm{ppm} \mathrm{O}_{2}(1848 \mathrm{ppm})$. An increased oxygen concentration in the build chamber leads to a $65 \%$ higher oxygen concentration in the bulk material. The surrounding powder is also known to have an increased oxygen concentration after the build job and might therefore exceed standard (ASTM B348) grade faster reducing the number of times it can be reused [50]. Nitrogen follows the same trend due to the proportionally increased nitrogen concentration in the build atmosphere. Nitrogen concentration could be quadrupled at higher oxygen concentrations (200 ppm) compared to the powder (62 ppm). This could be explained by the partial pressure of the gases, which increases, the higher the concentration in the atmosphere (Dalton's law). Thereby the overall pressure must remain constant [56]. A higher partial pressure will lead to an increased reaction rate. The concentration difference of the bulk material compared to the atmosphere is greater for nitrogen resulting in an increased nitrogen pickup. Hydrogen does not seem to be affected by the atmosphere and is stable at around $19 \mathrm{ppm}$. The dependence of the chemical composition of the bulk material on the oxygen and nitrogen concentration in the atmosphere could be reproduced during the fatigue build jobs.

Even at low oxygen concentration (2 ppm) in the build atmosphere an increase of oxygen in the bulk material of $351.6 \mathrm{ppm}$ could be found. The main source of oxygen in this case could be moisture in the powder $[57,58]$. To avoid further oxidation, a drying step before the build process could be applied. In order to avoid degradation of the powder a vacuum drying process would be favored.

The XRD patterns show a hcp $\alpha / \alpha^{\prime}$ structure known to literature. Between the $\alpha 002$ and $\alpha 101$ plane a shoulder of $\alpha 110$ known as $\beta$ phase (bcc) could be identified. Oxygen is known to stabilize the $\alpha$ phase. Due to the atomic radius it occupies the larger octahedral site of the hexagonal close packed structure [59].

The microstructural observations for stress relieved samples revealed a basketweave structure typical for L-PBF processed Ti-6Al-4 V. It is assumed to be $\alpha^{\prime}$-martensite formed inside the prior- $\beta$ grains [11]. A hardness of around $390 \mathrm{HV} 10$ indicates $\alpha^{\prime}$-martensite whereas HIPed samples have a Vickers hardness of around 335 HV10 increasing with the build chamber oxygen concentration [38,39]. HIPed samples do have a certain amount of $\beta$-phase reducing the hardness and tensile strength whilst increasing ductility.

HOLLANDERS ET AL. found an ultimate tensile strength of $1211 \mathrm{MPa}$ and a yield strength of $1100 \mathrm{MPa}$ which exceed the ASTM 2924 for Powder Bed Fused Ti-6Al-4 V requirements (ultimate tensile strength $895 \mathrm{MPa}$, yield strength $825 \mathrm{MPa}$ ) [60,61]. Conversely the elongation failure (6.5 $\%)$ was below the ASTM specification of $10 \%$ [62]. The increased strength of the material could be explained by the high cooling rate of the L-PBF samples resulting in a martensitic structure [63]. An ultimate tensile strength of $1203 \mathrm{MPa}$ could be observed for the $2 \mathrm{ppm}$ build job, which slightly increased to $1217 \mathrm{MPa}$ for the $600 \mathrm{ppm}$ build job. The

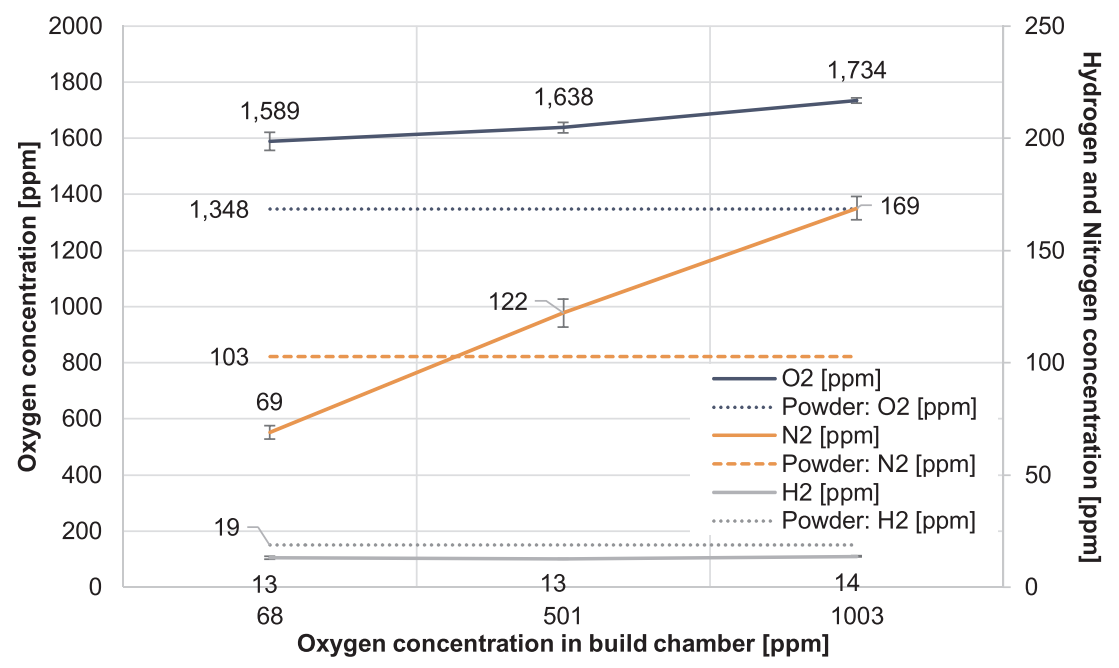

Fig. 21. $\mathrm{N}_{2}, \mathrm{O}_{2}$ and $\mathrm{H}_{2}$ concentration of the bulk material in relation to the oxygen concentration in the build atmosphere during L-PBF process of fatigue samples. 


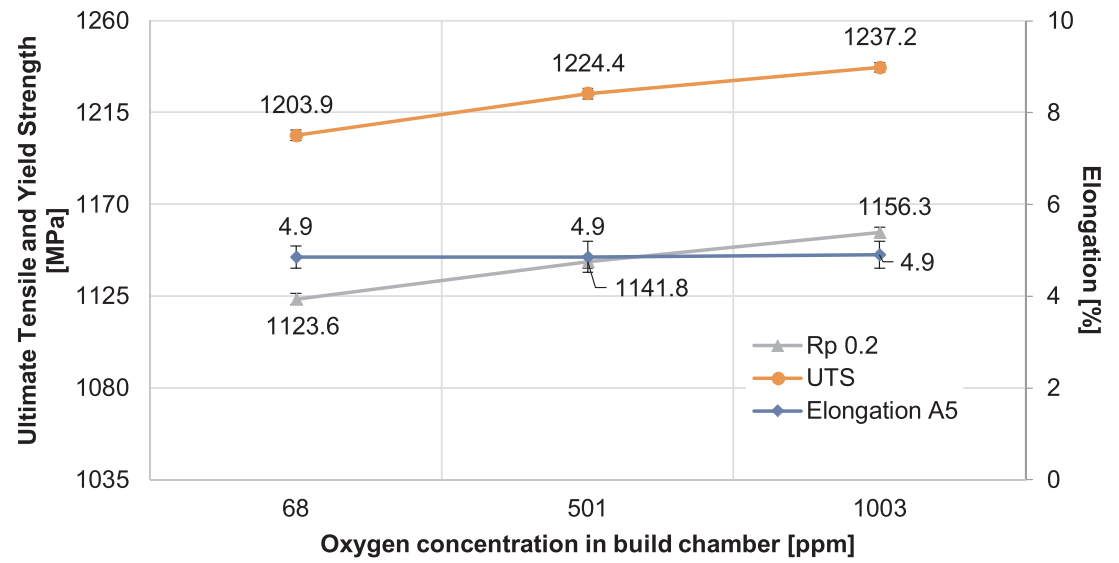

Fig. 22. Tensile strength and elongation in relation to oxygen concentration in the build atmosphere during L-PBF production process for fatigue samples.

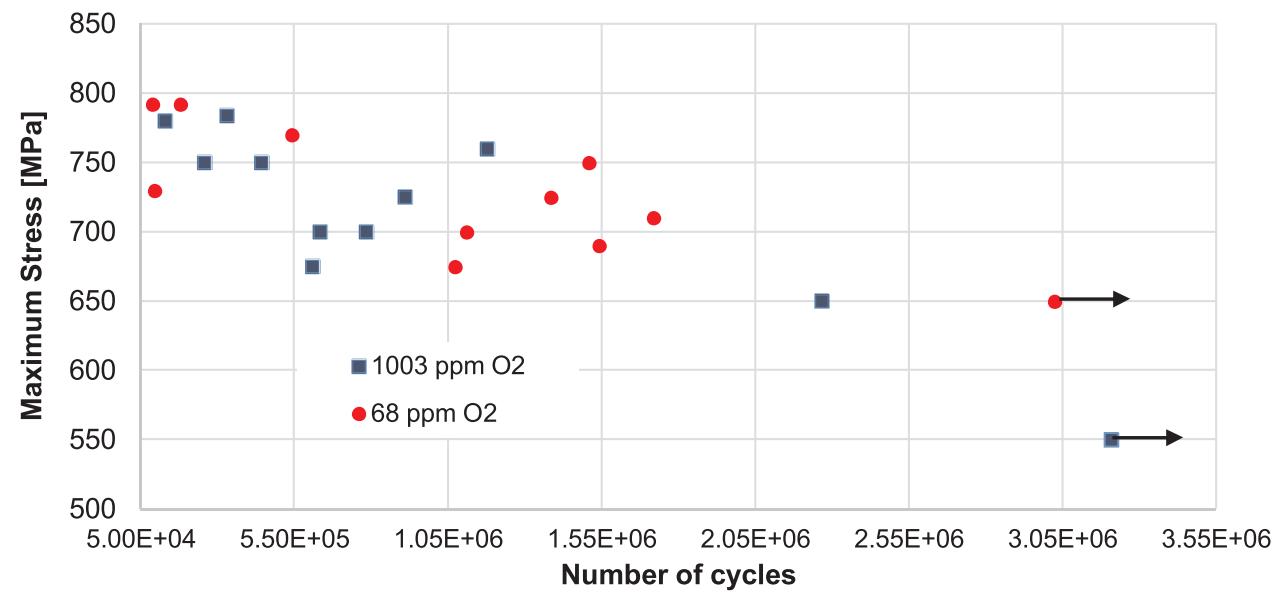

Fig. 23. Fatigue tests form samples with different oxygen concentration in the build atmospheres during the L-PBF process. Non-ruptured parts are marked with an arrow.

benchmark job had $1233 \mathrm{MPa}$. The mean standard error is $\pm 1.43 \mathrm{MPa}$. The yield strength follows the same trend, starting at $919 \mathrm{MPa}$ achieved at $2 \mathrm{ppm}$ and $980 \mathrm{MPa}$ for the benchmark job. The elongation is slightly decreasing, from $8.1 \%$ to $7.2 \%$, with increasing atmospheric oxygen during the build job. At $600 \mathrm{ppm}$ oxygen a minimum in elongation of $6.5 \%$ could be observed. Comparing the obtained results to the behavior of commercial pure titanium shows a similar trend [54]. An increased oxygen concentration in the bulk material leads to higher yield strength and ultimate tensile strength.

To investigate whether the deviation in tensile strength is due to varying oxygen concentrations in the build chamber or different porosities, five tensile samples were HIPed after being stress relieved. Similar to the stress relieved samples the UTS increases by $75 \mathrm{MPa}$ from $2 \mathrm{ppm}$ to $977 \mathrm{ppm}$. Due to the increased amount of $\beta$-phase, the elongation is significantly higher, reaching $16.8 \%$ for the samples where the atmosphere was controlled by the ADDvance ${ }^{\circledR} \mathrm{O}_{2}$ precision and 14 $\%$ for the L-PBF machine-controlled atmosphere. Although the HIPed samples are considered free of pores (density $99.99 \%$ ) the benchmark jobs show a high standard error (UTS $\pm 38.5 \mathrm{MPa}$, Elongation \pm 0.77 $\%)$. One influencing factor could be the increased brittleness, compared to the ones built at lower oxygen concentrations, correlating to the increased oxygen and nitrogen concentration of the material.

\section{Conclusion}

Whilst the oxygen and nitrogen concentration in the final parts increases with an elevated oxygen concentration in the build chamber, titanium oxide and nitride formation are very likely. Due to the high cooling rates during laser powder bed fusion the $\beta$-phase solidifies into primarily $\alpha^{\prime}$-martensite microstructures. This leads to embrittlement and decreasing elongation. HIPing at $920{ }^{\circ} \mathrm{C}$ increases the $\beta$-content leading to an increased elongation and reduced tensile strength and hardness. Further, Charpy tests, tensile samples and cubes were built horizontal, using an EOS M290 at varying oxygen concentrations in the build chamber $(0-1000 \mathrm{ppm})$ controlled by an ADDvance ${ }^{\circledast} \mathrm{O}_{2}$ precision. Additional tests regarding hardness, microstructure and chemical composition were performed to determine the importance of gas management during L-PBF. A second build job design was used to verify the results and investigate fatigue behavior. With an elevated oxygen concentration in the build chamber from $2 \mathrm{ppm}$ to $977 \mathrm{ppm}$, the following conclusions can be drawn:

- Oxygen concentration in the final parts increases from $1670 \mathrm{ppm}$ to 1848 ppm whilst nitrogen increases from 56 ppm to $200 \mathrm{ppm}$

- Tensile strength increased for stress relieved (1203 MPa to 1233 $\mathrm{MPa}$ ) and HIPed samples (1002 MPa to $1058 \mathrm{MPa}$ )

- Fatigues resistance tends to decrease

- Build atmospheres not precisely controlled, leads to a greater deviation in tensile strength for stress relieved and HIPed samples

Overall build jobs, the results are reproduceable showing that the gas composition inside the build chamber is an important parameter for the L-PBF process. A higher reproducibility can be achieved by precisely controlling the composition of the atmosphere. 

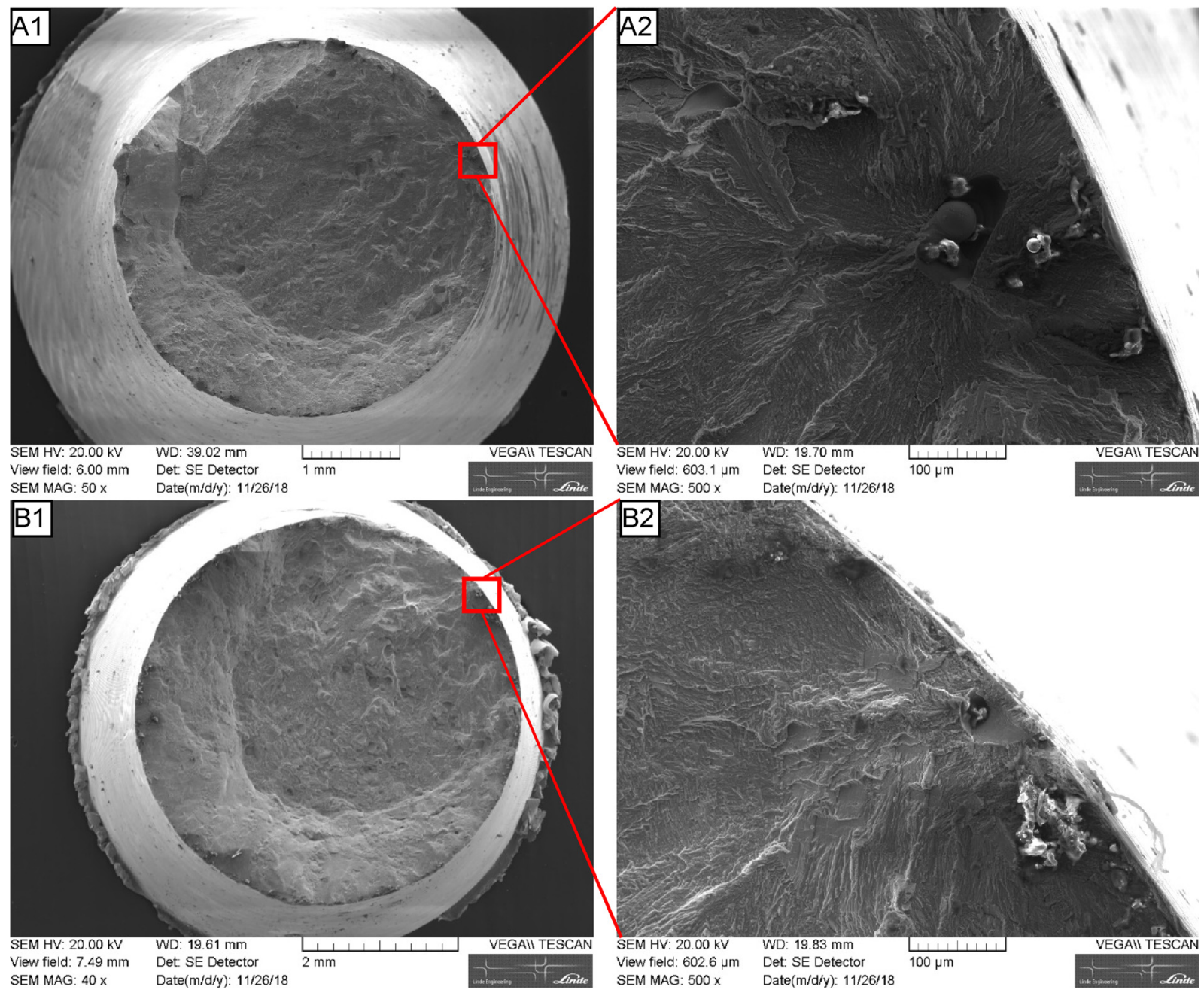

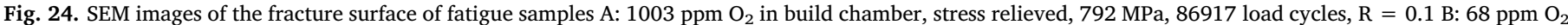
in build chamber, stress relieved, $700 \mathrm{MPa}, 631048$ load cycles, $\mathrm{R}=0.1$.

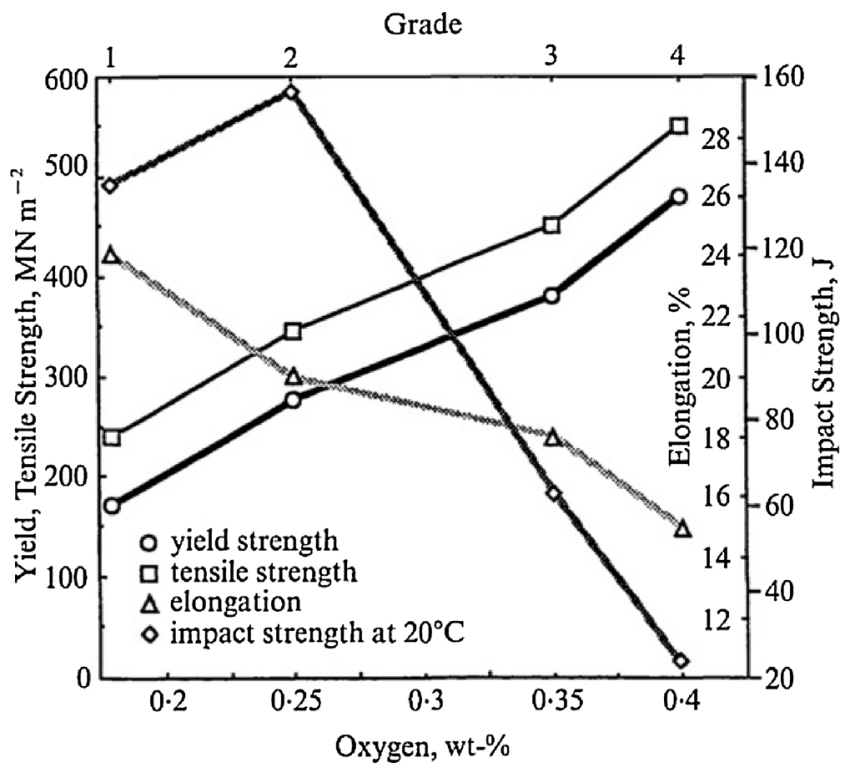

Fig. 25. Effect of oxygen concentration on the mechanical properties of commercially pure titanium [54]

\section{Declaration of Competing Interest}

The authors declare that they have no known competing financial interests or personal relationships that could have appeared to influence the work reported in this paper.

\section{References}

[1] E. Engblom, Effect of Oxygen Concentration in Build Chamber During Laser Metal Deposition of Ti-64 Wire, Stockholm, Sweden, (2018).

[2] P. Krakhmalev, Deformation baheviour and microstructure of Ti6Al4V manufactured by SLM, Phys. Procedia 83 (2016) 778-788.

[3] M.J. Donachie, Titanium-A Techinacal Guide, (2000), https://doi.org/10.5772/ 1844.

[4] E.W.C. Rodney, Boyer, Gerhard Welsch, Military Handbook Titanium and Titanium Alloys MIL-DBK-697 a, (1974).

[5] C. Leyens, M. Peters, Titanium and Titanium Alloys Fundamentals and Applications, WILEY-VCH Verlag GmbH \& Co. KGaA, Weinheim, 2003, https://doi.org/10.1002/ 3527602119.

[6] Z.Z. Fang, J.D. Paramore, P. Sun, K.S.R. Chandran, Y. Zhang, Y. Xia, F. Cao, M. Koopman, M. Free, Powder metallurgy of titanium-past, present, and future, Int. Mater. Rev. 63 (2018) 407-459, https://doi.org/10.1080/09506608.2017 1366003.

[7] J.L. Murray, H.A. Wriedt, The O-Ti (oxygen-titanium) system, J. Phase Equilibria Diffus. 8 (1987) 148-165, https://doi.org/10.1007/BF02873201.

[8] L. Thijs, J. Van Humbeeck, K. Kempen, E. Yasa, J.P. Kruth, Investigation on the inclusions in maraging steel produced by SLM, Int. Conf. Adv. Res. Virtual Rapid Prototyp. (2011) 297-304.

[9] J. Yang, H. Yu, J. Yin, M. Gao, Z. Wang, X. Zeng, Formation and control of martensite in Ti-6Al-4V alloy produced by selective laser melting, Mater. Des. 108 (2016) 308-318, https://doi.org/10.1016/j.matdes.2016.06.117. 
[10] Y. Robert, Simulation numérique du soudage du TA6V par laser YAG impulsionnel caractérisation expérimentale et modélisation des aspects thermomécaniques associés à ce procédé, (2007), p. 257.

[11] Y. Yang, Y.J. liu, J. Chen, H.L. Wang, Z.Q. Zhang, Y.J. Lu, S.Q. Wu, J.X. Lin, Crystallographic features of $\alpha$ variants and $\beta$ phase for Ti-6Al-4V alloy fabricated by selective laser melting, Mater. Sci. Eng. A 707 (2017) 548-558, https://doi.org/10. 1016/j.msea.2017.09.068.

[12] F. Brueckner, M. Riede, M. Mueller, F. Marquardt, M. Knoll, R. Willner, A. Seidel, E. Lopez, C. Leyens, E. Beyer, Fabrication of metallic multi-material components using Laser Metal Deposition, Solid Freeform Fabr. Symp. Proc. (2017) 2530-2538.

[13] L. Lü, J.Y.H. Fuh, Y.S. Wong, Laser-Induced Materials and Processes for Rapid Prototyping, (2001), https://doi.org/10.1007/978-1-4615-1469-5.

[14] K.C. Mills, Recommended Values of Thermophysical Properties for Selected Commercial Alloys, (2002), https://doi.org/10.1533/9781845690144.

[15] R. Ramakrishnaiah, A.A. Al kheraif, A. Mohammad, D.D. Divakar, S.B. Kotha, S.L. Celur, M.I. Hashem, P.K. Vallittu, I.U. Rehman, Preliminary fabrication and characterization of electron beam melted Ti-6Al-4V customized dental implant, Saudi J. Biol. Sci. 24 (2017) 787-796, https://doi.org/10.1016/j.sjbs.2016.05.001.

[16] S. Tammas-Williams, P.J. Withers, I. Todd, P.B. Prangnell, The effectiveness of hot isostatic pressing for closing porosity in titanium parts manufactured by selective electron beam melting, Metall. Mater. Trans. A Phys. Metall. Mater. Sci. 47 (2016) 1939-1946, https://doi.org/10.1007/s11661-016-3429-3.

[17] G. Rösel, P. Rodatz, D.F.H.J. Neugärtner, Ergebnisse einer optimalen Auslegung von Hardware und Motorsteuerungsfunktion für den Metallkatalysator mit innerem ausgleich Results of an optimal Design of Hardware and Engine, Aachener Kolloquium Fahrzeug- Und Mot. (2006).

[18] T.S. Auckenthaler, C.H. Onder, H.P. Geering, Modelling of a Solid-Electrolyte Oxygen Sensor Reprinted From : Electronic Engine Controls 2002, SAE Tech. Pap. Ser. (2018).

[19] DIN, 50125, Prüfung metallischer Werkstoffe - Zugproben, (2004).

[20] ASTM International, ASTM E23 - 18, Standard Test Methods for Notched Bar Impact Testing of Metallic Materials, ASTM Int., 2018, pp. 1-26, https://doi.org/ 10.1520/E0023-18.

[21] DIN EN, 6072:2011-06, Luft- und Raumfahrt - Metallische Werkstoffe Prüfverfahren - Ermüdungstest mit konstanter Amplitude, (2011).

[22] E.S.L.R.M. Fey, DE102006011894A1, 2006.

[23] X.P. Li, K.M. O’Donnell, T.B. Sercombe, Selective laser melting of Al-12Si alloy: enhanced densification via powder drying, Addit. Manuf. 10 (2016) 10-14, https:// doi.org/10.1016/j.addma.2016.01.003.

[24] I. Gibson, D.W. Rosen, B. Strucker, Additive Manufacturing Technologies: Rapid Prototyping to Direct Digital Manufacturing, Springer, 2010, https://doi.org/10. 1007/978-1-4419-1120-9.

[25] L. Cordova, M. Campos, T. Tinga, Revealing the effects of powder reuse for selective laser melting by powder characterization, JOM 71 (2019) 1062-1072, https://doi. org/10.1007/s11837-018-3305-2.

[26] R.W. Bochuan Liu, C. Tuck, I. Ashcroft, R. Hague, Investigation the Effect of Particle Size Distribution on Processing Parameters Optimisation in Selective Laser Melting Process, (2011), pp. 227-238.

[27] A.B. Spierings, N. Herres, G. Levy, Influence of the particle size distribution on surface quality and mechanical properties in AM steel parts, Rapid Prototyp. J. 17 (2011) 195-202, https://doi.org/10.1108/13552541111124770.

[28] R. Baitimerov, P. Lykov, D. Zherebtsov, L. Radionova, A. Shultc, K. Prashanth, Influence of powder characteristics on processability of AlSi12 alloy fabricated by selective laser melting, Materials (Basel) 11 (2018) 742, https://doi.org/10.3390/ ma11050742.

[29] J. DAWES, C. LANGLEY, J. CLAYTON, Optimizing metal powders for additive manufacturing: exploring the impact of particle morphology and powder flowability, Met. Powder Rep. 69 (2017) 1-5, https://doi.org/10.1016/S0026-0657(14) 70223-1.

[30] T. Abu-Lebdeh, R. Damptey, V. Lamberti, S. Hamoush, Powder packing density and its impact on SLM-Based additive manufacturing, Miner. Met. Mater. Ser. (2019) 355-367, https://doi.org/10.1007/978-3-030-05861-633.

[31] B. Moisă, Influence of chemical composition on stainless steels mechanical properties 1 introduction 2 Alloying elements in stainless steel, Math. Mathods Tech. Eng. Environ. Sci. (2011) 95-100.

[32] J. Oh, B. Lee, S. Cho, S. Lee, G. Choi, J. Lim, Oxygen effects on the mechanical properties and lattice strain of Ti and Ti-6Al-4V, Met. Mater. Int. (2011) 2-6, https://doi.org/10.1007/s12540-011-1006-2.

[33] I.I. Kornilov, V.V. Vavilova, L.E. Fykin, R.P. Ozerov, S.P. Solowiev, V.P. Smirnov, Neutron diffraction investigation of ordered structures in the titanium-oxygen system, Metall. Trans. 1 (1970) 2569-2571, https://doi.org/10.1007/BF03038386.

[34] ASTM, E407, E407-07 Standard Practice for Microetching Metals and Alloys, ASTM Int. 07, 2015, pp. 1-22, https://doi.org/10.1520/E0407-07R15E01.2.

[35] D. Agius, K. Kourousis, C. Wallbrink, A review of the as-built SLM Ti-6Al-4V mechanical properties towards achieving fatigue resistant designs, Metals (Basel) 8 (2018) 75, https://doi.org/10.3390/met8010075.

[36] W. Xu, M. Brandt, S. Sun, J. Elambasseril, Q. Liu, K. Latham, K. Xia, M. Qian, Additive manufacturing of strong and ductile Ti-6Al-4V by selective laser melting via in situ martensite decomposition, Acta Mater. 85 (2015) 74-84, https://doi.org/ 10.1016/j.actamat.2014.11.028.

[37] M. Shunmugavel, A. Polishetty, G. Littlefair, Microstructure and mechanical properties of wrought and additive manufactured Ti-6Al-4V cylindrical bars, Procedia Technol. 20 (2015) 231-236, https://doi.org/10.1016/j.protcy.2015.07. 037.

[38] E. Sallica-Leva, R. Caram, A.L. Jardini, J.B. Fogagnolo, Ductility improvement due to martensite $\alpha$ ' decomposition in porous Ti-6Al-4V parts produced by selective laser melting for orthopedic implants, J. Mech. Behav. Biomed. Mater. 54 (2016) 149-158, https://doi.org/10.1016/j.jmbbm.2015.09.020.

[39] M. Losertová, V. Kubeš, Microstructure and mechanical properties of selective laser melted Ti6Al4V alloy, IOP Conf. Ser. Mater. Sci. Eng. 266 (2017), https://doi.org/ 10.1088/1757-899X/266/1/012009.

[40] J. He, D. Li, W. Jiang, L. Ke, G. Qin, Y. Ye, Q. Qin, D. Qiu, The martensitic transformation and mechanical properties of Ti6Al4V prepared via selective laser melting, Materials (Basel) 12 (2019), https://doi.org/10.3390/ma12020321.

[41] E. Santecchia, P. Mengucci, A. Gatto, E. Bassoli, L. Denti, B. Rutkowski, A. CzyrskaFilemonowicz, G. Barucca, Powder bed fusion of biomedical Co-Cr-Mo and Ti-6Al4V alloys: microstructure and mechanical properties, Adv. Mater. Res. 1151 (2019) 3-7 doi:10.4028/www.scientific.net/amr.1151.3.

[42] B. Zhou, J. Zhou, H. Li, F. Lin, A study of the microstructures and mechanical properties of Ti6Al4V fabricated by SLM under vacuum, Mater. Sci. Eng. A 724 (2018) 1-10, https://doi.org/10.1016/j.msea.2018.03.021.

[43] B. Wysocki, P. Maj, R. Sitek, J. Buhagiar, K. Kurzydłowski, W. Święszkowski, Laser and electron beam additive manufacturing methods of fabricating titanium bone implants, Appl. Sci. 7 (2017) 657, https://doi.org/10.3390/app7070657.

[44] G. Lütjering, J.C. Williams, Titanium, Springer, n.d.

[45] X. Zhao, S. Li, M. Zhang, Y. Liu, T.B. Sercombe, S. Wang, Y. Hao, R. Yang, L.E. Murr, Comparison of the microstructures and mechanical properties of Ti-6Al-4V fabricated by selective laser melting and electron beam melting, Mater. Des. 95 (2016) 21-31, https://doi.org/10.1016/j.matdes.2015.12.135.

[46] G.P. Dinda, L. Song, J. Mazumder, Fabrication of Ti-6Al-4V Scaffolds by Direct Metal Deposition, (n.d.). doi:10.1007/s11661-008-9634-y.

[47] L. Thijs, F. Verhaeghe, T. Craeghs, J. Van Humbeeck, J.P. Kruth, A study of the microstructural evolution during selective laser melting of Ti-6Al-4V, Acta Mater. 58 (2010) 3303-3312, https://doi.org/10.1016/j.actamat.2010.02.004.

[48] P. Taylor, E. Yasa, J. Deckers, J. Kruth, M. Rombouts, J. Luyten, E. Yasa, J. Deckers, J. Kruth, M. Rombouts, J. Luyten, Charpy impact testing of metallic selective laser melting parts, Virtual Phys. Prototyp. 5 (2) (2010) 89-98, https://doi.org/10.1080/ 17452751003703894.

[49] A.M. Muiruri, M. Maringa, W. du Preez, L. Masu, Variation of impact toughness of As-Built dmls Ti6Al4V (Eli) specimens with temperature, South Afr. J. Ind. Eng. 29 (2018) 284-298, https://doi.org/10.7166/29-3-2076.

[50] L. Grainger, Investigating the Effects of Multiple Re-use of Ti6Al4V Powder in Additive Manufacturing, (2016).

[51] L.C. Ardila, F. Garciandia, J.B. González-Díaz, P. Álvarez, A. Echeverria, M.M. Petite, R. Deffley, J. Ochoa, Effect of IN718 recycled powder reuse on properties of parts manufactured by means of selective laser melting, Phys. Procedia 56 (2014) 99-107, https://doi.org/10.1016/j.phpro.2014.08.152.

[52] ASTM B348-13, Standard Specification for Titanium and Titanium Alloy Bars and Billets, n.d. doi:10.1520/B0348-13.2.

[53] A. Schadensanalyse, VDI 3822 Schäden durch mechanische Beanspruchung, Verfahrenstechnik. (2008)

[54] M.L. Wasz, F.R. Brotzen, R.B. McLellan, A.J. Griffin, Effect of oxygen and hydrogen on mechanical properties of commercial purity titanium, Int. Mater. Rev. 41 (2014) 1-12, https://doi.org/10.1179/imr.1996.41.1.1.

[55] H. Conrad, Effect of interstitial solutes on the strength and ductility of titanium, Prog. Mater. Sci. 26 (1981) 123-403, https://doi.org/10.1016/0079-6425(81) 90001-3.

[56] T. Kuwana, The oxygen and nitrogen absorption of iron weld metal during arc welding, Int. Inst. Weld. Congr. Join. Res. (1990).

[57] C. Pauzon, E. Hryha, P. Forêt, L. Nyborg, Effect of argon and nitrogen atmospheres on the properties of stainless steel $316 \mathrm{~L}$ parts produced by laser-powder bed fusion, Mater. Des. 179 (2019) 107873, , https://doi.org/10.1016/j.matdes.2019.107873.

[58] L. Thijs, Microstructure and Texture of Metal Parts Produced by Selective Laser Melting, Katholieke Universiteit Leuven, 2014.

[59] R. Montanari, G. Costanza, M.E. Tata, C. Testani, Lattice expansion of Ti-6Al-4V by nitrogen and oxygen absorption, Mater. Charact. 59 (2008) 334-337, https://doi. org/10.1016/j.matchar.2006.12.014.

[60] Standard Specification for Wrought Titanium-6Aluminum-4Vanadium ELI (Extra Low Interstitial) Alloy for Surgical Implant Applications (UNS, n.d. doi:10.1520/ F0136-13.2.

[61] D.A. Hollander, M. Von Walter, T. Wirtz, R. Sellei, B. Schmidt-Rohlfing, O. Paar, H.J. Erli, Structural, mechanical and in vitro characterization of individually structured Ti-6Al-4V produced by direct laser forming, Biomaterials 27 (2006) 955-963, https://doi.org/10.1016/j.biomaterials.2005.07.041.

[62] S. Requirements, M. Containing, L. Than, T. Percent, C. Titanium, Standard Specification for Additive Manufacturing Titanium-6 Aluminum-4 Vanadium With Powder Bed Fusion 1, ASTM F2924-14. (2018), https://doi.org/10.1520/F292414.2.

[63] J. Tong, C.R. Bowen, J. Persson, A. Plummer, Mechanical properties of titaniumbased Ti-6Al-4V alloys manufactured by powder bed additive manufacture, Mater Sci. Technol. (United Kingdom) 33 (2017) 138-148, https://doi.org/10.1080/ 02670836.2016.1172787. 